\title{
A extensão universitária atuando na avaliação e na melhoria da qualidade da água subterrânea consumida por uma comunidade carente de água potável
}

\author{
Maria da Graça Zepka Baumgarten \\ Universidade Federal do Rio Grande | Brasil \\ dqmmgzb@furg.br
}

\section{Mariele Lopes Paiva}

Universidade Federal do Rio Grande | Brasil marieledepaiva@gmail.com

\section{Horácio Rodrigo Souza Rodrigues}

Universidade Federal do Rio Grande | Brasil horacio.rodrigues@furg.br

\section{Resumo}

A Ilha dos Marinheiros (1400 hab.) pertence à cidade do Rio Grande (RS). Nela, não há suprimento de água potável, sendo consumida a água subterrânea. Em 2013, foi aí desenvolvido o projeto de extensão "A água do seu poço é ferruginosa? 0 conhecimento acadêmico a serviço da comunidade". Foram analisados os níveis de ferro na água consumida em cada uma das 309 casas habitadas, usando-se um kit analítico. Foi constatado que em $41,75 \%$ das casas há consumo de água ferruginosa (ferro $>0,3 \mathrm{mg} / \mathrm{L}$ ). Em cada casa, foi entregue um laudo do resultado com informações sobre tratamentos caseiros de remoção do ferro da água. A partir da conscientização dos ilhéus, eles agiram na busca de consumirem água de melhor qualidade.

\section{Palavras-chave}

Consumo, Água subterrânea ferruginosa, Ilha dos Marinheiros/Rio Grande/RS. 


\section{Introdução}

Apesar de terem maior proteção dos contaminantes externos, as águas subterrâneas podem apresentar problemas de qualidade, principalmente quanto à sua potabilidade. Um dos mais frequentes é a presença de ferro em excesso (águas ferruginosas), de origem antrópica ou natural, o que pode limitar o uso da água tanto para uso doméstico como industrial (Lima e Pedrozo, 2001). Além disso, os hidróxidos de ferro presentes na água podem controlar a mobilidade biogeoquímica de metais tóxicos, como chumbo, cobre, cádmio e arsênio (Corbett, 1995).

A ingestão de ferro em doses moderadas é indispensável à saúde humana, pois é um nutriente essencial para o metabolismo normal das células. Mas em quantidades elevadas, o ferro pode ser tóxico, já que, quando metabolizado excessivamente, tem toxicidade intracelular sistêmica. Comunidades que consomem águas ferruginosas são, rotineiramente, submetidas ao risco de intoxicação por ferro e demais elementos tóxicos associados. Além das implicações negativas à saúde, o excesso de ferro na água disponibilizada nas casas pode acarretar amarelamento de roupas brancas durante a lavagem e de louças sanitárias, além de conferir sabor e odor desagradáveis à água e aos alimentos com ela preparados (Lima e Pedrozo, 2001).

Essa realidade representa um problema para a comunidade da Ilha dos Marinheiros (em torno de $40 \mathrm{~km}^{2}$ de área), pertencente ao município de Rio Grande (200.000 hab.) localizada no estuário da Lagoa dos Patos, no extremo sul do Brasil (Figura 1). Nessa ilha, além de não haver rede de coleta de esgotos, não há suprimento de água potável, sendo consumida a água subterrânea pelos 1.324 habitantes. 0 recurso mais utilizado, atualmente, para obtenção da água é a bomba elétrica, que puxa a água subterrânea, para a mesma ser armazenada em caixas d'água antes do uso caseiro. Atualmente, muitos moradores da ilha ainda restringem-se ao sistema de poços artesianos.

O projeto de extensão "A água do seu poço é ferruginosa? O conhecimento acadêmico a serviço da comunidade" foi desenvolvido na ilha em 2012/2013 e avaliou os níveis de ferro na água consumida em cada casa. 0 projeto partiu do preceito de que a universidade, por meio do vínculo pesquisa/extensão, tem também o compromisso de contribuir com as comunidades externas à academia. Essa contribuição foi baseada na transmissão do conhecimento e/ou da aplicação de tecnologia desenvolvidos no ambiente universitário. Com isso, estas ações de extensão universitária almejam mudanças positivas na qualidade de vida da população da Ilha dos Marinheiros, que se queixa da presença de ferro na água que consomem, bem como o desenvolvimento sustentável da vida na ilha. 
A extensão universitária atuando na avaliação e na melhoria da qualidade da água subterrânea

O acima referido projeto se propôs a informar aos ilhéus as concentrações de ferro na água consumida em cada casa, bem como os prejuízos à qualidade de vida decorrentes do consumo de água ferruginosa. Além disso, se propôs a ensinar para os ilhéus ações caseiras para diminuir os níveis de ferro na água subterrânea antes de ser consumida.

O presente artigo relata como a execução do referido projeto de extensão incentivou e permitiu a atuação da comunidade da Ilha dos Marinheiros, na criação de políticas públicas e requisições de ações que busquem o saneamento básico da ilha, coerentes com as necessidades da própria comunidade, principalmente em termos de melhorias na qualidade da água consumida.

\section{Metodologia}

\section{1 Área do estudo}

A Ilha dos Marinheiros (Figura 1, a seguir) é considerada o segundo distrito do município de Rio Grande. Está dividida em cinco áreas: Porto do Rey, que é a sede do distrito; Marambaia (leste), que tem maior proximidade com o canal principal de navegação do estuário da Lagoa dos Patos (Canal do Rio Grande); Bandeirinhas (oeste), onde está localizada a ligação da ilha com Rio Grande (aterros e ponte) e as áreas Fundos da Ilha e Coréia (norte).

Na periferia da ilha, nas margens da única rua existente (ou estrada que circunda a ilha), é que se encontram as casas dos ilhéus e as áreas destinadas ao cultivo de legumes, hortaliças e afins, assim como os galpões de armazenamento da produção local, a igreja, os salões comunitários, as quatro escolas, o posto de saúde, etc. As 468 casas oficialmente existentes na ilha são térreas, relativamente isoladas umas das outras, predominantemente simples e de pequeno porte, sendo a maioria de madeira.

No centro da ilha, próximas às áreas de dunas de areias claras e às lagoas naturais formadas por afloramento de água subterrânea, se encontram plantações de monocultivos de Pinus Elliottis (Ilustração 1, a seguir). Aproximadamente, 400 ha encontram-se cobertos por esse florestamento exótico. 


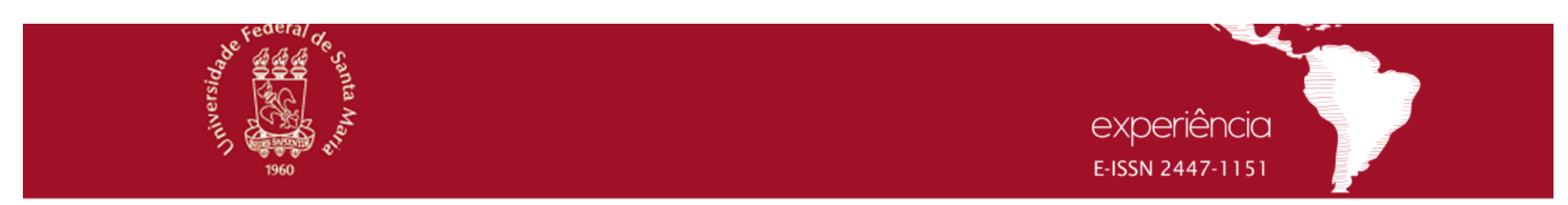

A extensão universitária atuando na avaliação e na melhoria da qualidade da água subterrânea

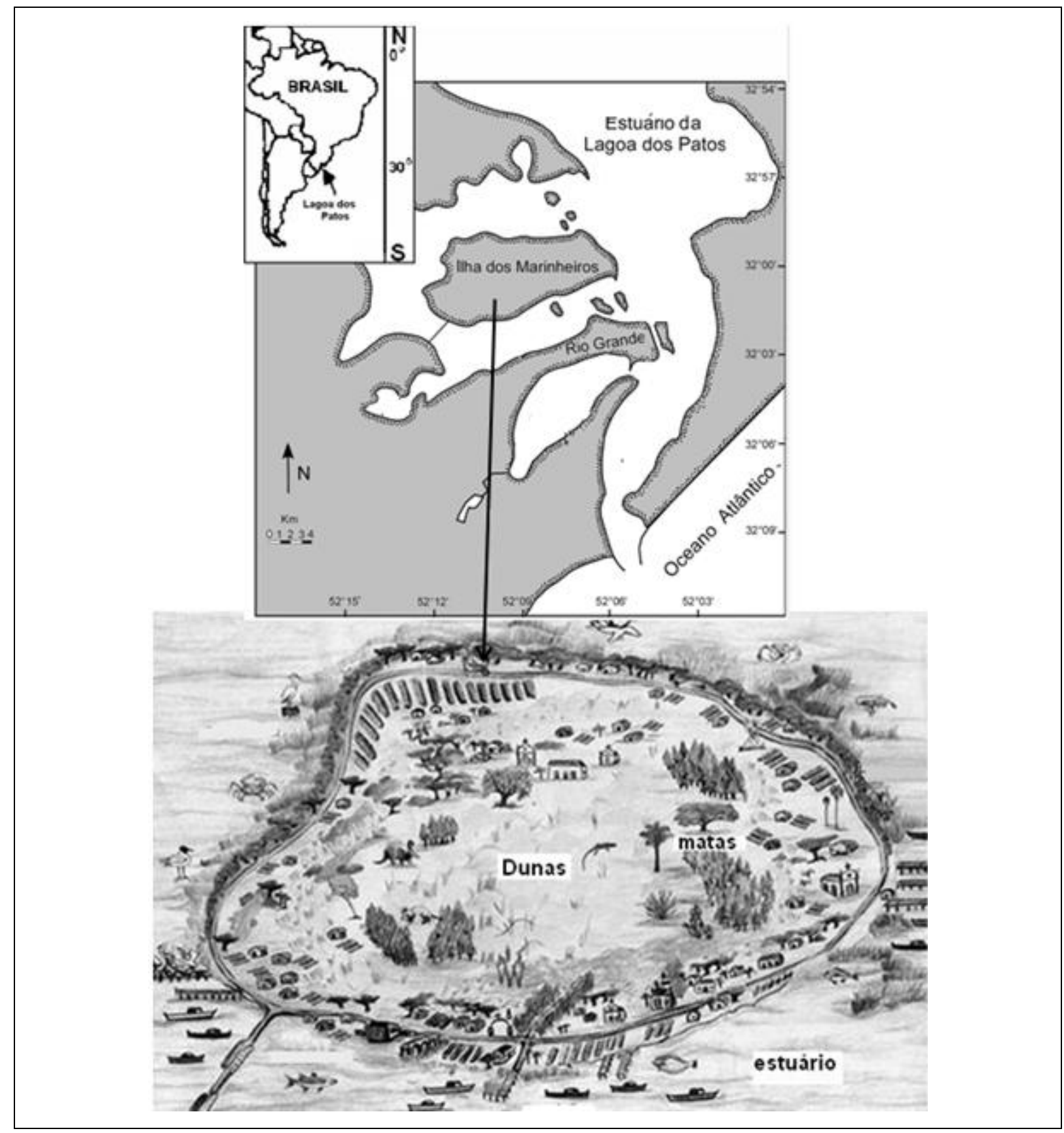

Figura 1: Estuário da Lagoa dos Patos (RS) e o esquema da Ilha dos Marinheiros, com suas atividades e ocupações. Fonte: extraído do folder "Ilha dos Marinheiros, descubra esse tesouro". Projeto Costa SUL. NEMA/FURG, sem data.

Fonte: Luciane Goldberg

\section{Análise da água consumida na região}

Em cada casa visitada na ilha, foi amostrada a água da torneira da cozinha e, nessa água, foi analisado o nível de ferro dissolvido total, por meio do uso de um kit analítico portátil, descrito em Baumgarten et al. (2014) ( Ilustração 2). 0 resultado foi fornecido no próprio local 
A extensão universitária atuando na avaliação e na melhoria da qualidade da água subterrânea

da coleta, em menos de 10 minutos, sem necessidade de transportar a amostra para o laboratório. A seguir, foi avaliado o nível de acidez da água consumida em cada casa, usando-se um potenciômetro digital portátil.

O kit analítico identificador do nível de água ferruginosa contém tubos de ensaio, onde são colocadas as amostras de água a serem analisadas. Em cada amostra são adicionados sucessivamente quatro reagentes químicos, segundo um roteiro metodológico baseado em adição de um determinado número de gotas de cada um dos reagentes. Esses reagentes são previamente preparados em laboratório de química, conforme roteiro descrito em Baumgarten et al. (2014) e, como componentes do kit, são levados ao local da análise em frascos tipo contagotas ( Ilustração 2, a seguir).

A partir da reação química entre amostra e reagentes, é formado o composto alaranjado ortofenantrolina ferrosa, caso a amostra possuir ferro, cuja intensidade do tom laranja é proporcional ao nível de contaminação desse metal na água testada. Depois disso, compara-se a amostra colorida com uma cartela impressa, contendo uma escala com seis tons da cor laranja (cartela colorimétrica). Cada um dos tons da cor laranja corresponde gradativamente a um nível de contaminação por ferro, sendo estes: sem contaminação; contaminação muito baixa; baixa (concentrações menores que 0,3mg/L de ferro); contaminação média; alta e muito alta (concentrações maiores que $0,3 \mathrm{mg} / \mathrm{L}$ ).

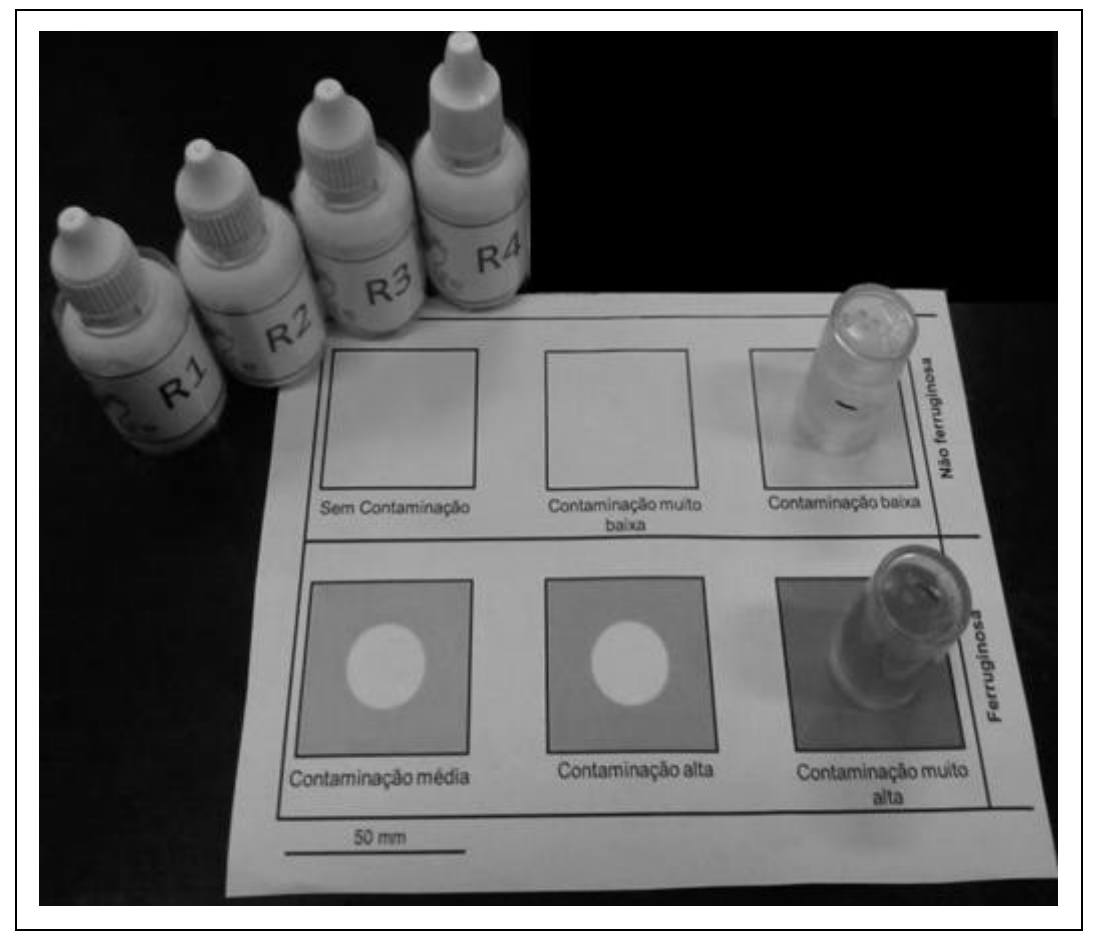

Ilustração 2: Kit analítico para análise do ferro na água subterrânea, contendo os quatro reagentes (R1 a R4). Sobre a cartela, apresentando seis tons da cor laranja, estão duas amostras submetidas à análise, com dois níveis diferentes de contaminação.

Fonte: Baumgarten et al. (2014). 
A extensão universitária atuando na avaliação e na melhoria da qualidade da água subterrânea

A partir dessa análise, em cada casa, foi fornecido um laudo impresso contendo o resultado do nível de ferro da água, além de um livreto ilustrado com textos enfocando ( Ilustração 4): (i) a problemática do consumo de água ferruginosa e (ii) sugestões de métodos caseiros acessíveis para a remoção do ferro da água subterrânea.

No livreto também foram fornecidas instruções de como fazer a correta manutenção dos filtros caseiros nas casas que os possuíam e informações sobre pequenas adaptações que podem ser feitas nas caixas d'água para facilitar a remoção do ferro na água, além das instruções corretas de como e quando realizar a limpeza destas. Em cada casa, foi aplicado um questionário socioambiental, visando a investigar a realidade, a visão e a expectativa dos moradores com relação à problemática da água consumida na ilha.

\section{Resultados e discussão}

Do total de casas da ilha, foram avaliadas 309, porque as demais casas não estavam habitadas durante os dias das amostragens (Ilustração 3, a seguir). Os resultados mostraram que, em média, 41,75\% das casas da ilha são supridas com água ferruginosa. As cinco áreas da ilha não apresentam o mesmo percentual de casas com consumo de água ferruginosa. A maior incidência dessa contaminação ocorreu na área Coréia (79,3\% das casas avaliadas), seguida pela Marambaia (50,5\%), Fundos da Ilha (50,0\%) e Bandeirinhas (42,9\%), sendo inferior somente no Porto Rey, com apenas $14,1 \%$ das casas abastecidas com água ferruginosa. A partir desses resultados, os ilhéus foram concientizados da intensidade e das áreas de maior incidência do problema. Além disso, com a realidade comprovado por dados analíticos, o poder público poderá adotar ações mais direcionadas e, portanto, mais efetivas na busca de soluções ou pelo menos melhorias da água consumida pelos ilhéus.

Teoricamente, a água subterrânea da ilha deveria ser de boa qualidade, levando em consideração a composição do solo areno-argiloso, que funciona como um filtro natural. Entretanto, conforme evidenciaram as análises, dentro de uma mesma área, a concentração de ferro varia entre as casas, estando o aumento da mesma diretamente relacionado à acidez da água subterrânea captada e à menor profundidade do ponto de captação de cada casa.

Nos casos de casas que consomem água ferruginosa e ácida, os prejuízos à saúde são maiores, pois além dos problemas causados pelo excesso de ferro, a acidez favorece mais ainda os distúrbios gástricos (Lima e Pedrozo, 2001). Segundo esses autores, a acidificação das águas é uma das causas do enriquecimento de ferro na água subterrânea, porque contribui para a dissolução de sais e partículas do solo rico em ferro que armazena a água. A acidificação também pode ser favorecida pelo desenvolvimento, nas paredes do poço, de ferrobactérias, 
A extensão universitária atuando na avaliação e na melhoria da qualidade da água subterrânea

principalmente na sua parte mais superficial. Estes organismos, por meio de processos de respiração e consequente liberação de $\mathrm{CO}_{2}$, acidificam a água pelo favorecimento da produção de gás carbônico.

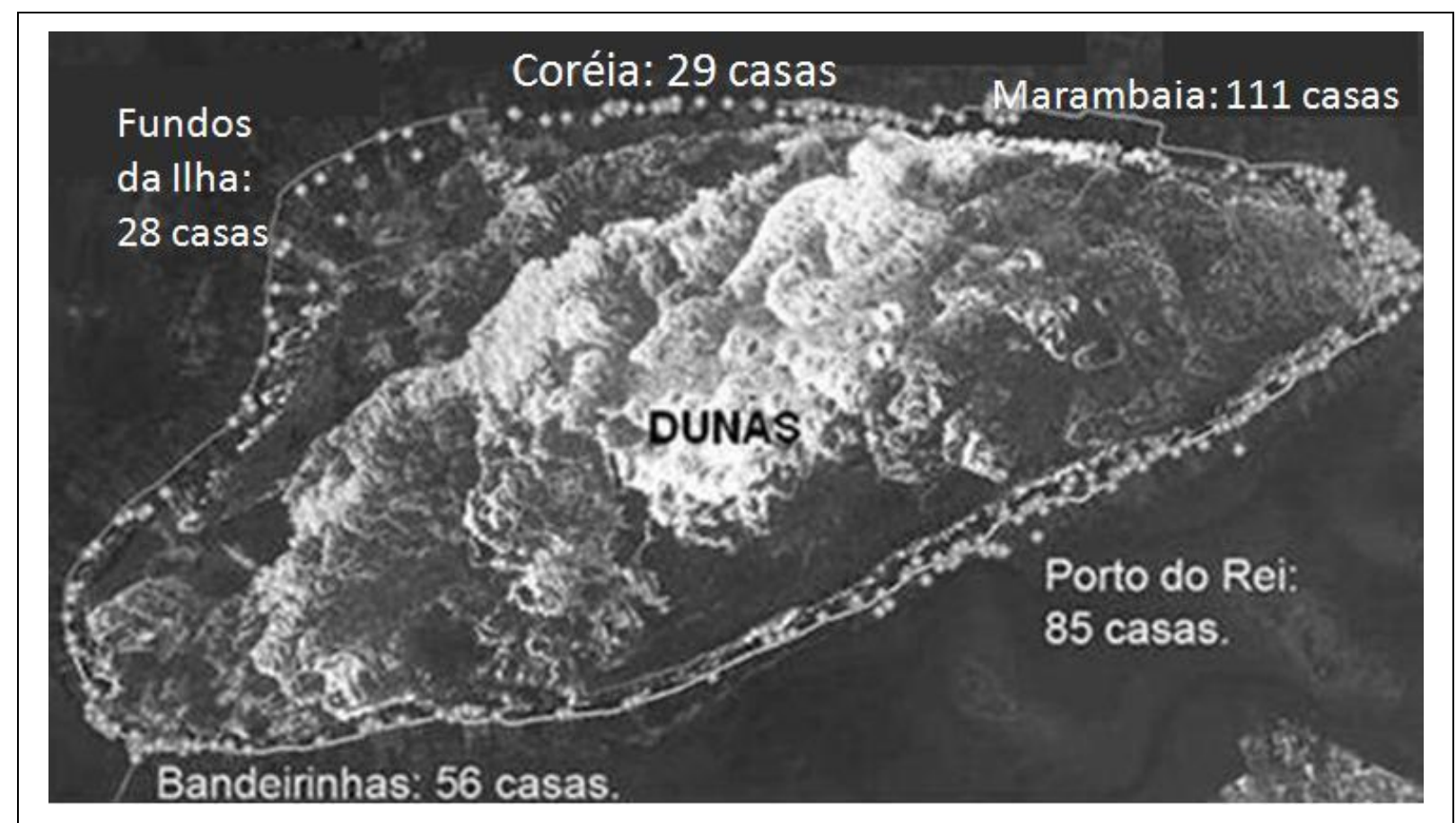

lustração 3 - Ilha dos Marinheiros com as suas cinco áreas, onde estão identificadas as 309 casas avaliadas em cada área, representadas por círculos nas margens da ilha onde elas se situam. Fonte: extraído de Baumgarten et al. (2014).

Outro fator que contribuiu para a acidificação do lençol freático de algumas áreas da Ilha dos Marinheiros foi a presença de monocultivos de Pinus sp., com imensas matas plantadas na ilha para extração comercial de madeira. Essas matas resultam em cobertura do solo superficial, principalmente com acículas que despencam das árvores, formando uma relativa impermeabilização. Isso ainda se soma à matéria orgânica vegetal em decomposição acumulada na base das árvores, o que diminui a oxigenação do solo e aumenta a acidez na água subterrânea mais superficial (Wally et al., 2010). As folhas e acículas do Pinus sp. não apodrecem facilmente, porque as bactérias responsáveis por essa degradação não se adaptaram ao nosso clima. Portanto, uma monocultura dessa espécie gera um impacto ecológico significativo (Auer et al., 2007).

As monoculturas de Pinus sp. na Ilha dos Marinheiros, se encontram próximas aos cordões de dunas de areias claras silicosas, que margeiam as pequenas lagoas centrais. A presença dessas matas diminuiu a biomassa e a biodiversidade natural do ambiente (outros poucos vegetais sobreviveram nas áreas de mata) e causa alteração do ciclo hidrológico (consome a água subterrânea e diminuem o nível das lagoas) (citado em Programa Costa Sul, 2006). 
A extensão universitária atuando na avaliação e na melhoria da qualidade da água subterrânea

simples e baratas podem melhorar a qualidade da água consumida e, assim, eles valorizaram a assistência que estavam recebendo da equipe deste projeto. A partir disso, os moradores de todas as casas foram incentivados a adquirirem massivamente esses filtros.

Além disso, os ilhéus foram instruídos sobre procedimentos corretos para facilitar a limpeza das velas dos filtros. Isso foi necessário, porque eles se queixaram que as velas dos mesmos ficavam entupidas e saturadas em poucos dias (colmatavam), perdendo a eficiência de filtração, quando a água ferruginosa era colocada para ser filtrada sem um prévio tratamento adequado.. Foi-lhes ensinado, então, que para maior durabilidade da eficiência da vela do filtro, os ilhéus deveriam precipitar previamente o ferro da água antes de filtrá-la: a recomendação foi de que adicionassem 5 gotas de hipoclorito de sódio por litro de água ferruginosa, e após deixassem esse água descansar exposta ao ar por uma noite. Depois, colocassem no filtro apenas a água sobrenadante, já que o ferro floculado permanecia no fundo do recipiente onde a água descansou (LIMA; PEDROZO, 2001).

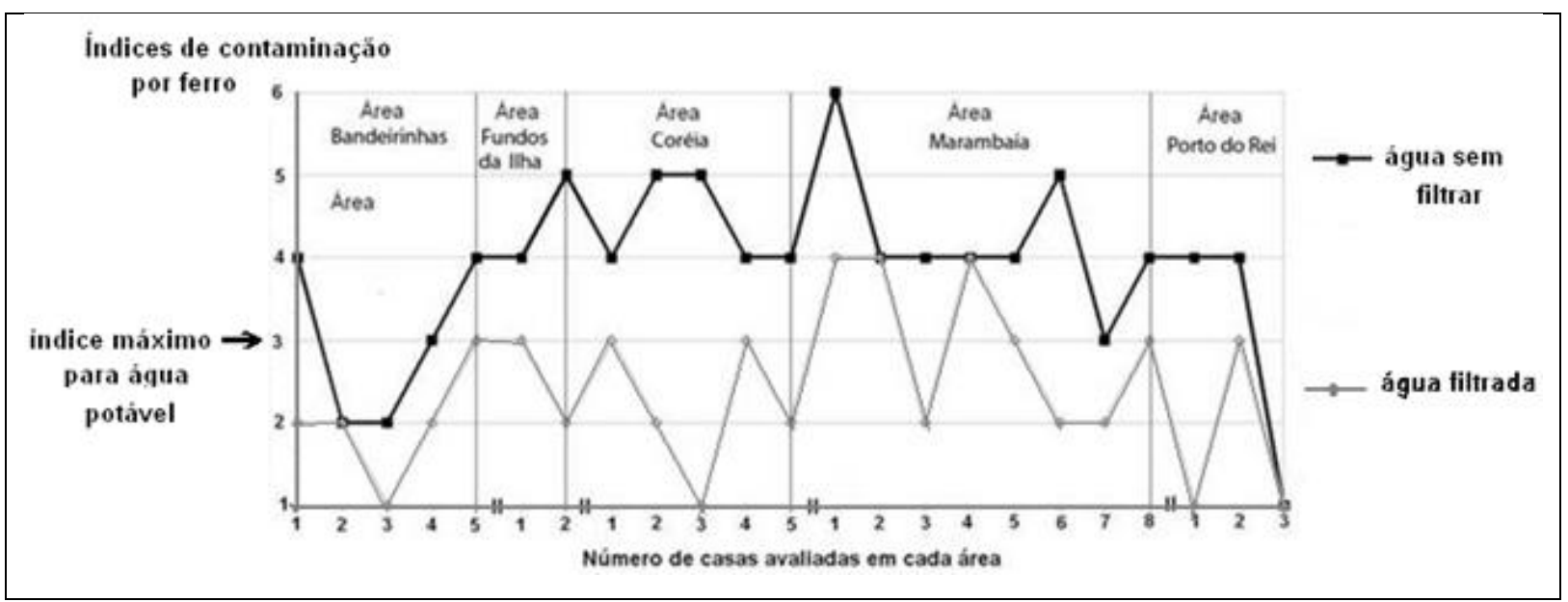

Ilustração 5 - Eficiência do uso dos filtros na remoção de ferro de águas subterrâneas consumidas nas 23 casas das cinco áreas da Ilha dos Marinheiros que fazem uso desse recurso. Significado dos índices do eixo esquerdo do gráfico: 1- sem contaminação; 2- muito baixa; 3- baixa; 4- média; 5- alta; 6- muito alta. Fonte: Baumgarten et al. (2014).

Com relação aos questionários aplicados em cada casa, estes evidenciaram que a maioria dos ilhéus se queixa de não dispor de água "boa para beber" e enfrenta sérios problemas com o uso da água ferruginosa no cotidiano, em termos de qualidade de vida. Uma queixa constante foi o problema das constantes incrustações nas tubulações e nas caixas d'água domiciliares onde costumam armazenar a água subterrânea antes do consumo ( Ilustração 6). 
A extensão universitária atuando na avaliação e na melhoria da qualidade da água subterrânea

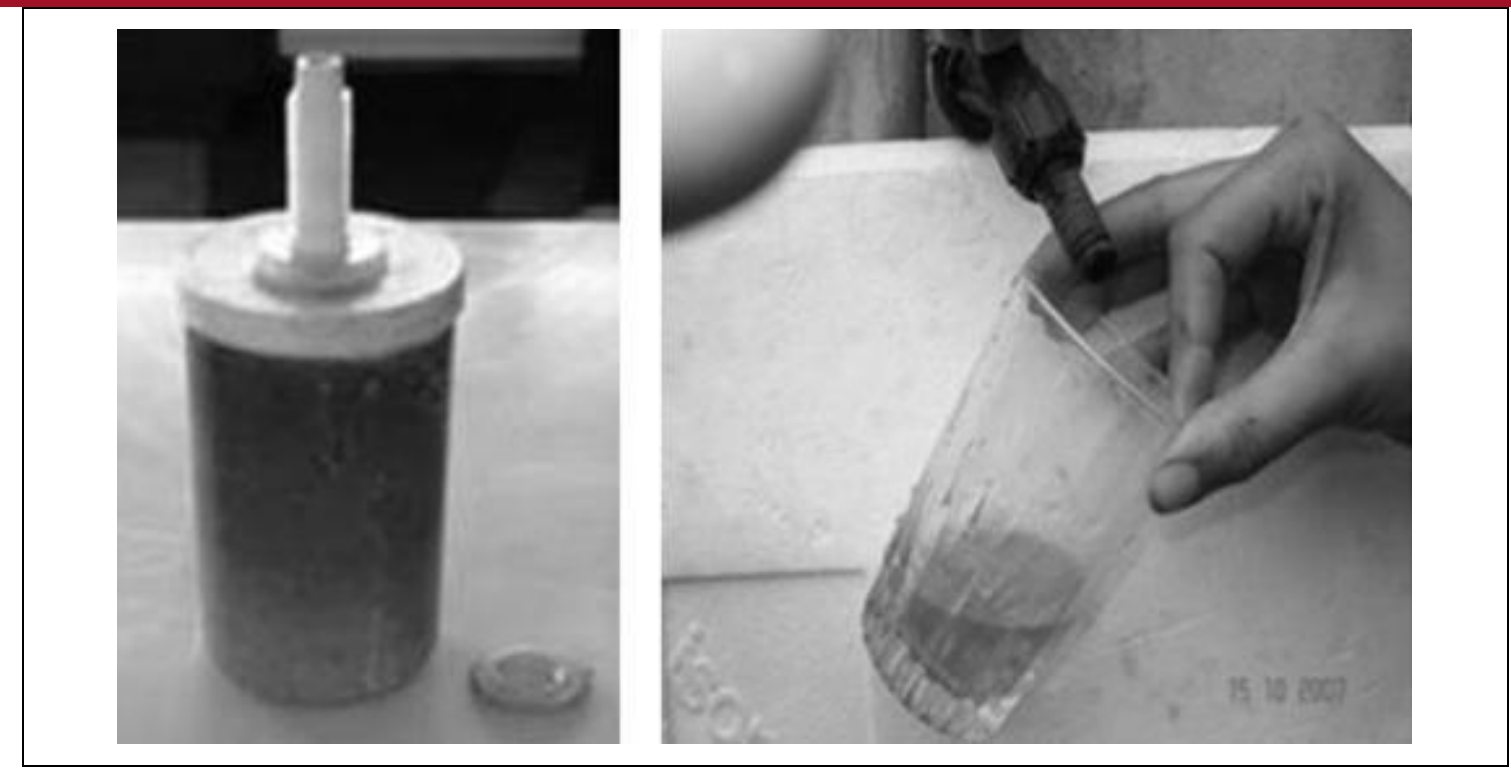

Ilustração 6: Incrustações de ferro na vela do filtro e aspecto da água ferruginosa consumida em algumas casas da Ilha dos Marinheiros.

Fonte: Baumgarten et al. (2014).

A parit dos conhecimentos e esclarecimentos fornecidos por este projeto aos ilhéus, eles passaram a investir mais na busca dos seus direitos legais em termos de melhoria do saneamento básico e de qualidade de vida na ilha. Além do mais, a partir deste projeto, eles disseram se sentirem mais conscientizados e bem informados da realidade da água que consomem e da problemática ambiental com que convivem, seja pela falta de água potável, de rede de coleta de esgotos, de usos do solo da ilha para plantações de monoculturas, entre outros problemas ambientais.

Nesse sentido, a Prefeitura Municipal da cidade do Rio Grande, incitada pelos próprios moradores da ilha, incluiu a problemática diagnosticada neste projeto sobre a água consumida na Ilha dos Marinheiros, no Plano Municipal de Saneamento Básico da cidade - PMSB, que foi aprovado em 2013 e entrou em vigor a partir de 2014 (ENGEPLUS, 2013, Produto 3). Dessa forma, no plano, foram oficializadas duas alternativas para a Ilha dos Marinheiros, visando melhorar a água consumida: implantação de dois poços profundos de acesso público na ilha e incentivo e/ou apoio técnico e financeiro para a utilização de cisternas públicas ou particulares armazenadoras de água da chuva, somado à instalação de planta de tratamento de água.

\section{Considerações finais}

\subsection{Em termos da metodologia}


A extensão universitária atuando na avaliação e na melhoria da qualidade da água subterrânea

A aplicação de um kit analítico portátil para análises instantâneas do nível de ferro propiciou análises massivas da qualidade da água consumida em cada casa da ilha, esclarecendo os ilhéus sobre a realidade de cada casa. A entrega de um laudo analítico e materiais didáticos impressos após a análise documentou o resultado, instrumentalizando e motivando os moradores de cada casa da ilha em suas requisições e direitos na busca de água de melhor qualidade.

Portanto, esse kit analítico de muito fácil uso e pouco preço de montagem é uma estratégia bastante recomendada para projetos comunitários de avaliação da água consumida casa a casa, em comunidades carentes de água potável canalizada, principalmente em se tratando de projetos de extensão.

\subsection{Em termos políticos e de gestão pública}

Este projeto evidenciou que comunidades rurais, como a Ilha dos Marinheiros, que não dispõem de saneamento básico e vivem em certo isolamento do centro urbano e das infraestruturas que este oferece, precisam muito de assistência especial do poder público e de ações de extensão de centros de geração do conhecimento e tecnologia, como as universidades locais.

Nesse sentido, projetos de extensão universitária, que visem a disseminar o conhecimento acadêmico a serviço de comunidades carentes são bem-vindos e muito recomendados. Além disso, oferece aos alunos extensionistas uma oportunidade única de vivenciarem na própria comunidade suas futuras profissões ou os conteúdos ensinados na academia.

As sugestões oferecidas de estratégias caseiras e o correto uso e limpeza de filtros e caixas d'água para remoção do ferro foram eficientes nas casas que as adotaram. Isso torna gratificante o esforço de conscientização e esclarecimento aos ilhéus feito pela equipe deste projeto.

Esse diagnóstico revelou que o consumo de água ferruginosa se concentra em três áreas da ilha (em ordem decrescente tem-se Coréia, Marambaia e Bandeirinhas), onde a metade ou mais da metade das casas convive com este problema de saúde pública. Nessas áreas, a ação do poder público deve ser intensificada, para amenizar os efeitos desse problema na qualidade de vida desses ilhéus, principalmente porque a maioria deles é muito carente em muitos aspectos, principalmente em termos de nível educacional e recursos financeiros.

Por isso, se entende que o presente projeto atendeu a essa proposta e beneficiou a comunidade dessa ilha, pois gerou um diagnóstico detalhado da qualidade da água consumida pelos ilhéus nas cinco áreas da ilha, evidenciando as diferenças entre elas e identificando os 
focos do problema e possíveis causas e soluções caseiras ou oficiais, a curto e médio prazo.

O diagnóstico gerado representou, portanto, uma ferramenta e um detalhamento técnico da problemática. Seu uso em políticas públicas que visam à melhoria da qualidade de vida dos ilhéus proporcionou a oficialização, no Plano Municipal de Saneamento Básico de Rio Grande, de propostas de soluções massivas. A partir deste projeto, os ilhéus devem continuar cobrando do poder público todas as promessas documentadas em 2013, no referido plano.

Como consequência deste projeto de extensão, a comunidade foi munida com subsídios técnicos e com um diagnóstico da realidade da qualidade da água por eles consumida, para participarem ativamente na criação das políticas municipais de saneamento na ilha.

\subsection{Continuidade do projeto}

Este projeto teve continuidade em 2015, contemplando análises das bactérias fecais e do fósforo (como quimioindicador de contaminação por matéria orgânica e fertilizantes) nas casas da Ilha dos Marinheiros que apresentaram água ferruginosa ou tem poços de captação de água subterrânea perto das fossas sépticas. Para tanto, também estão sendo usados kits analíticos específicos. 0 kit referente à análise do fósforo fornece resultado instantâneo,assim como o de ferro (a amostra de água contaminada adquire diferentes tons de azul), e é similar àquele usado para o ferro, mudando os reagentes e a reação química (PINHEIRO JR. et al., 2010). Para análise das bactérias, será usado o kit Colitest ${ }^{\circledR}$ marca LPK. As casas identificadas com maior contaminação e mais carentes serão contempladas com filtros equipados com velas filtrantes e terão acompanhamento técnico- analítico gratuito pela equipe do projeto. ${ }^{1}$

\section{Referências}

AUER, C. G.; GHIZELINI, A. M.; PIMENTEL, I. C. Decomposição fúngica de acículas em plantios de Pinus. Revista Pesquisa Florestal Brasileira, Colomba, n. 54. p. 127-138, 2007.

BAUMGARTEN, M. G. Z.; PAIVA, M. L.; RODRIGUES, H. S. Kit analítico simplificado: uma ferramenta para avaliação massiva da qualidade da água subterrânea. Revista Água Subterrânea, São Paulo, v. 28, n. 2, p: 94-104, 2014.

CORBETT, J. V. Accidental poisoning with iron supplements. MCT - The American Journal of Maternal Child Nursing, São Francisco, v. 20, n. 4, p. 234, 1995.

ENGEPLUS, Engenharia e Consultoria Ltda. Elaboração do Plano Municipal de saneamento Básico do Rio Grande. Produto 3 - Prognóstico e Proposição de Alternativas para o Sistema de Saneamento. 140 p. Prefeitura Municipal do Rio Grande. SMMA. 2013.

SMMA notifica FLOPAL para controle e erradicação de Pinus sp. na Ilha dos Marinheiros. Jornal Agora, Geral, Rio Grande, RS, 25 maio 2015. 
LIMA, I. V.; PEDROZO, M. F. Ecotoxicologia do ferro e seus compostos. Série Cadernos de Referência Ambiental, Centro de Recursos Ambientais, Salvador, v. 4, 2001.

PINHEIRO, Jr.; BAUMGARTEN, M. G. Z; SOUZA, M. L. A poluição das águas por matéria orgânica: uma abordagem didática para o ensino fundamental. In: QUADRADO, R. P. et al. (orgs.). Ecos do Sul: conhecer os ecossistemas costeiros é tri legal! Rio Grande, RS: Editora da FURG, 2010. p. 168-187.

PROGRAMA Costa Sul. Plano de Manejo Ambiental da Ilha dos Marinheiros, Rio Grande, RS, 2006. 13p.

RELATÓRIO Final para análise e discussão. Versão 3. Rio Grande, RS: FURG, 2006. 43 p.

WALLY, M. K.; BAUMGARTEN, M. G. Z.; CASARTELLI, M. R.; PAIVA, M. L. Influência das áreas florestadas por Pinus sp. (Ilha dos Marinheiros, Rio Grande/RS) no enriquecimento em ferro da água subterrânea. In: XXII Semana Nacional de Oceanografia. Anais... Itanhaém, RJ, 2010.

1 Os autores agradecem à Diretoria de Extensão da FURG - DIEX e ao Ministério da Educação e Cultura pelo apoio financeiro. Agradecem ao acadêmico da FURG Pedro Waslow e ao Químico Edi Pinheiro Júnior pelas colaborações durante as análises e visitas às casas.

The university extension actingin evaluating and improving groundwater quality consumed by a community in need of drinking water

\section{Abstract}

The Ilha dos Marinheiros (1400 inhab.) belongs to the city of Rio Grande (RS). They consumed groundwater since there is no supply of drinking water. In 2013 it was developed the extension project "The water from your well is ferruginous? Academic knowledge to community service." Iron levels were analyzed in the water consumed in each of the 309 inhabited houses by using an analytical kit. It was found the ferruginous water consumption (iron $>0.3 \mathrm{mg} / \mathrm{L}$ ) for $41.75 \%$ of the houses. Each house obtained a result report with information on homemade removal of iron from water treatments. From the awareness of the islanders, they acted in the pursuit of quality water consumed.

\section{Keywords}

Consumption, Ferruginous groundwater, Ilha dos Marinheiros/Rio Grande/RS.
La actuación de extensión universitaria en la evaluación y mejora de la calidad del agua subterránea consumida por una comunidad en necesidad de agua potable

\section{Resumen}

La Ilha dos Marinheiros (1.400 hab.) pertenece a la ciudad de Rio Grande (RS). Enella no hay suministro de agua potable y por eso se consume el agua subterránea. En 2013 fue desarrollado el proyecto de extensión "El agua de su pozo es ferruginosa? El conocimiento académico al servicio de la comunidad." Se analizaron los niveles de hierro en el agua consumida en cada uno de los 309 hogares habitados, por medio del uso de un kit analítico. Fue identificado que en $41,75 \%$ de los hogares se consume el agua ferruginosa (hierro $>0,3 \mathrm{mg} / \mathrm{L}$ ). En cada casa fue entregado el resultado con informaciones sobre tratamientos caseros de eliminación del hierro del agua. A partir de la conciencia de los isleños, ellos empezaron la búsque da por el agua de calidad.

\section{Palabras clave}

Consumo, Agua subterránea ferruginosa, Ilha dos Marinheiros/Rio Grande/RS. 
A extensão universitária atuando na avaliação e na melhoria da qualidade da água subterrânea

Original submetido em: 7 jul. 2015

Aceito para publicação em: 25 jul. 2015

Sobre os autores:

\section{Maria da Graça Zepka Baumgarten}

Professora Titular do Instituto de Oceanografia da Universidade Federal do Rio Grande (FURG), Rio Grande do Sul, Brasil. Mestre em Oceanografia Biológica pela FURG. Extensionista desde 2012 na DIEX/FURG. Atua nas áreas de qualidade de águas naturais e subterrâneas e efluentes. Responsável pelo Laboratório de Ensino de Química e atua no Laboratório de Hidroquímica desde 1980.

\section{Mariele Lopes Paiva}

Doutoranda em Oceanografia pela FURG. Oceanóloga. Mestre em Oceanografia Química, Física e Biológica.

\section{Horácio Rodrigo Souza Rodrigues}

Graduando do Curso de Oceanologia pela FURG. 